University of Nebraska - Lincoln

DigitalCommons@University of Nebraska - Lincoln

\title{
A Three-Dimensional Field Study of Solute Transport Through Unsaturated, Layered, Porous Media 1. Methodology, Mass Recovery, and Mean Transport
}

\author{
T. R. Ellsworth \\ University of Illinois at Urbana-Champaign \\ W. A. Jury \\ University of California - Riverside \\ F. F. Ernst \\ University of California - Riverside \\ P. J. Shouse \\ U.S. Salinity Laboratory
}

Follow this and additional works at: https://digitalcommons.unl.edu/usdaarsfacpub

Part of the Agricultural Science Commons

\footnotetext{
Ellsworth, T. R.; Jury, W. A.; Ernst, F. F.; and Shouse, P. J., "A Three-Dimensional Field Study of Solute Transport Through Unsaturated, Layered, Porous Media 1. Methodology, Mass Recovery, and Mean Transport" (1991). Publications from USDA-ARS / UNL Faculty. 497.

https://digitalcommons.unl.edu/usdaarsfacpub/497
}

This Article is brought to you for free and open access by the U.S. Department of Agriculture: Agricultural Research Service, Lincoln, Nebraska at DigitalCommons@University of Nebraska - Lincoln. It has been accepted for inclusion in Publications from USDA-ARS / UNL Faculty by an authorized administrator of DigitalCommons@University of Nebraska - Lincoln. 


\title{
A Three-Dimensional Field Study of Solute Transport Through Unsaturated, Layered, Porous Media 1. Methodology, Mass Recovery, and Mean Transport
}

\author{
T. R. ELLSWORTH ${ }^{1}$ \\ U.S. Salinity Laboratory, Riverside, California \\ W. A. JURY AND F. F. ERNST \\ Department of Soil and Environmental Science, University of California, Riverside \\ P. J. SHOUSE \\ U.S. Salinity Laboratory, Riverside, California
}

\begin{abstract}
A field experiment is reported which monitored the three-dimensional movement of cubic solute plumes through an unsaturated, loamy sand soil. The plumes were created with one of two methods, a two-dimensional flux application and an initial resident distribution. Soil coring was used to sample resident concentrations for the three solutes studied. The data were analyzed using the method of moments. In addition to the solute transport experiments, a detailed set of physical properties of the field was obtained by excavating three pits to a depth of $5.0 \mathrm{~m}$ and also by taking soil cores throughout the study area. This paper explains the experimental methodology, summarizes the relevant site characteristics, and describes the observed transport based on the zeroth and first order spatial moments. Mass balance varied between 78 and $138 \%$. The field-averaged gravimetric water content and dry bulk density were used to accurately predict the mean vertical plume displacements. The plumes spread relatively little in the horizontal direction.
\end{abstract}

\section{INTRODUCTION}

Many chemicals enter and move through unsaturated soil as part of a compact plume. A solute plume may originate at the soil surface as a consequence of a spill or a leaking surface tank. It may also emanate from within the vadose zone by leaking through the bottom of a disposal pond or subsurface storage tank. The dissolution of solids, such as the leachate underneath a fly ash pit, may also create a chemical plume. In all of these scenarios, a contaminant plume is created which will likely migrate downward (depending on the soil moisture regime) toward an underlying water resource.

There are numerous reasons for wanting to improve the understanding of how a chemical moves through unsaturated soil. First, in many contamination episodes such as waste spills, the only information available is the volume of fluid that enters the soil and the area over which it infiltrated. Without an understanding of the degree of lateral dispersion of the plume, it is not possible to estimate even roughly the downward penetration of the spill. In the absence of a preliminary means for making this assessment, expensive and time-consuming soil concentration measurements must be made over a dense grid in the soil to characterize the plume geometry. Furthermore, even when the initial volume

\footnotetext{
${ }^{1}$ Now at Department of Agronomy, University of Illinois at Champaign-Urbana.

Copyright 1991 by the American Geophysical Union.

Paper number 91WR00183.

0043-1397/91/91WR-00183\$05.00
}

of a spill is known precisely from a remedial investigation, it will often be necessary to allow additional water to enter the soil either as part of the cleanup strategy, or because it is not possible to protect the entire soil area over the spill from water infiltration. Therefore, accurate future projection of the spill migration per unit of water input is an essential part of a design strategy for cleanup or waste isolation.

At the present time, a validated three-dimensional solute transport model capable of accurately predicting spill migration and dispersion in the unsaturated zone does not exist. Several candidate model approaches are available for this problem, yet model validation based on field research poses a formidable task.

In fact, the even more elementary problem of predicting the mean solute position as a function of time has been unexpectedly difficult in the unsaturated zone. Butters et al. [1989] observed that the field scale $(0.64 \mathrm{ha})$ downward velocity of a surface-applied bromide pulse leached with bidaily sprinkler irrigation was significantly slower (up to a factor of 2 ) in the surface $1.2 \mathrm{~m}$ than the velocity predicted by the piston flow model using the measured net applied water flux and the measured volumetric water content. This anomaly was present whether viewed at the field scale using the area average solution concentration measurement, or when looked at locally by analyzing individual solution sampler breakthrough curves. This finding is in agreement with field research by Elabd et al. [1988] who observed a slower mean velocity for a tritiated water pulse than estimated with piston flow. However, Jaynes et al. [1988] found the opposite to be tue, with the observed mean solute displacement much greater than predicted on the basis of 
piston flow. Russo et al. [1989a, b] showed that the mean downward displacement of water could be significantly affected by soil water hysteresis, profile heterogeneity normal to the direction of flow, or immobile water. Each of these effects were shown to obscure the relationship between mean downward transport and estimates made using the so-called piston flow model for solute displacement.

Field studies which have examined the three-dimensional nature of solute transport in the vadose zone are relatively scarce. McCord et al. [1988] conclude from field observations that considerable anisotropy in hydraulic conductivity exists for unsaturated conditions. These conclusions were supported by tracer experiments at the same locations, with considerable lateral and vertical variability observed in the tracer movement. Stephens et al. [1988] studied transport on a $30 \mathrm{~m} \times 30 \mathrm{~m}$ area and observed significant variations in vertical solute velocities, as well as considerable lateral spreading. Kung [1990] observed extreme variability in transport of a dye tracer through an unsaturated sandy soil. Based on his observations, he concluded that the current theory of solute transport in the vadose zone was not realistic.

Progress in developing solute transport descriptions in three dimensions has been more rapid in saturated soil. Large-scale comprehensive solute transport experiments have been conducted under intensive monitoring in groundwater [Mackay et al. 1986; Killey and Moltyaner, 1988] and have been accompanied by the development of a stochastic continuum model by Dagan [1984, 1987]. This model predicts the extent of solute spreading longitudinal and transverse to the direction of motion from estimates of local hydraulic conductivity variations. Comparison of this model with mean displacement and dispersion of a waste plume moving through an aquifer has yielded good agreement [Freyberg, 1986; Barry et al., 1988].

Two factors limit the application of the Dagan model to unsaturated soil. First, current stochastic continuum models require stationarity along the direction of flow, a circumstance commonly met in groundwater but almost never in the unsaturated zone. Second, under saturated flow conditions, the solute velocity is proportional to the saturated hydraulic conductivity, whereas in unsaturated soil the connection between solute velocity and soil properties is far more complex. As a result, even in stationary soil, the number of local property measurements that must be taken to evaluate the solute velocity variations is extensive.

From the preceding discussion, it is apparent that there is a need to examine the three-dimensional nature of solute transport in unsaturated soil. In an attempt to monitor transverse and longitudinal dispersion during transport, a three-dimensional field study, reported herein, was performed at the same field site used for the one-dimensional study of Butters et al. [1989]. The objectives of the present study are (1) to obtain a quantitative field-scale description of a cubic plume of solute as it varies over space and time while moving downward through an unsaturated soil, (2) to characterize the degree of transverse and longitudinal solute spreading during the transport process, specifically during the transit through layers of different texture at the site, and (3) to obtain an experimental data base from which model assumptions and/or theory may be developed or validated. This paper reports measurements of the physical characteristics of the field, describes the experimental methodology of

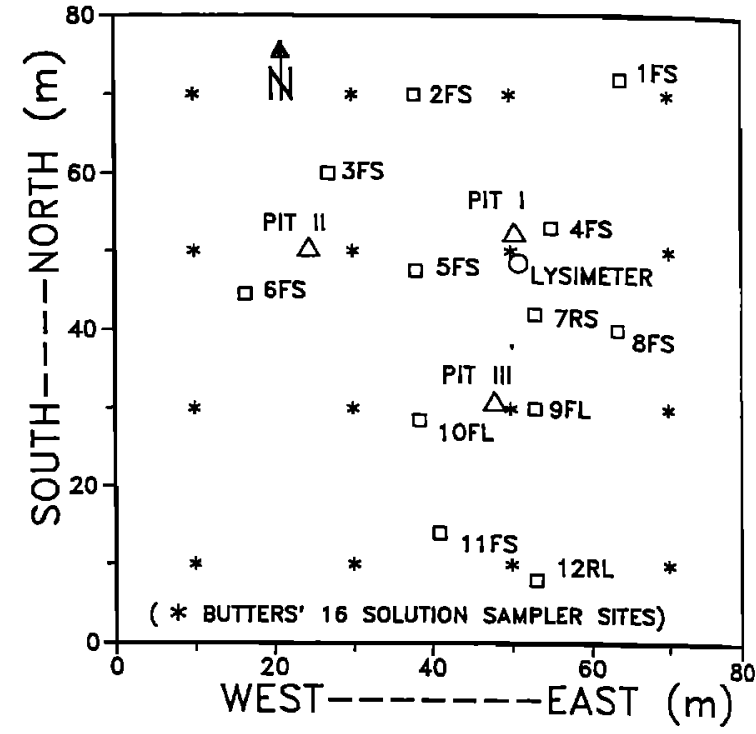

Fig. 1. Etiwanda field site, with locations of individual plots, excavation pits, and lysimeter. Each plot symbol has the following format: [location][application method][plot size][plot sample event] where "location" is an integer (1-12) which indicates the relative location of the plot, 1 representing the site farthest north and 12 the site farthest south, "application method" is denoted by a capital letter, $\mathrm{F}$ for flux application and $\mathrm{R}$ for initial resident distribution, "plot size" is either L for large $(2.0 \mathrm{~m}$ by $2.0 \mathrm{~m}$ ) or $S$ for small (1.5 $\mathrm{m}$ by $1.5 \mathrm{~m}$ ), and "plot sample event" is $\mathrm{a}, \mathrm{b}$, or c for the first, second, or third sampling, respectively.

the transport experiment, and compares the mass balance and first order moment estimates (location of the center of mass) of the several solutes used in the study. An accompanying paper describes solute dispersion processes in the experiment [Ellsworth and Jury, this issue].

\section{Materials ANd Methods}

\section{Field Description}

The solute plume experiments were performed over an 18-month period between May 1987 and October 1988 on a field site at Etiwanda, California. The soil is a nearly level Tujunga loamy sand that is of alluvial origin, well drained, with minimal horizon development (mixed, thermic, Typic Xeropsamment [Woodruff, 1980]).

Twelve sites were selected for study from within the 0.64-ha field used in the experiment reported by Butters et al. [1989]. Figure 1 shows the location of these sites relative to Butters' 16 solution sampler sites, as well as the location of a weighing lysimeter and three excavation pits used to characterize the physical properties of the field. The definition of the plot symbol codes used in this study are also given in the caption of Figure 1. In 1977 an established grape vineyard was cleared from the field. Since 1977 the site has been used for agricultural research by the University of California, Riverside, including occasional cropping. Three pits were dug to $5 \mathrm{~m}$ at the field site in order to obtain detailed visual observations of soil structure and to determine texture and bulk density variations with depth. Two bulk density samples (using cores of size $7.62 \mathrm{~cm}$ diameter by $7.62 \mathrm{~cm}$ length) were taken from each pit at $10-\mathrm{cm}$ intervals between the surface and the $5 \mathrm{~m}$ depth. These cores 
were carefully driven horizontally into the shaved sidewall of the pits to obtain approximately undisturbed soil samples. Butters [1987] measured the particle size distribution in the field from samples obtained by soil coring. To supplement his results, particle size analyses were performed using the pipette method [Day, 1965] on replicates from each bulk density sample for one of the pits. Thus, in the present study, four particle size analyses were performed for each $10-\mathrm{cm}$ interval to a depth of $5 \mathrm{~m}$.

Three inorganic tracers $\left[\mathrm{Ca}\left(\mathrm{NO}_{3}\right)_{2}, \mathrm{KCl}\right.$, and $\left.\mathrm{H}_{3} \mathrm{BO}_{3}\right]$, all applied in solution phase, were used in this research. Prior to solute application, the soil was thoroughly leached by sprinkler irrigation (with solute-free water) for 2 months, after which soil cores were taken to determine residual concentrations. Residual nitrate and chloride concentrations were approximately 3 orders of magnitude below the lowest planned solute application concentrations.

\section{Solute Application}

Two methods of solute application, a two-dimensional flux application ( $F$ ), on 10 of the sites, and an initial resident distribution (R), on two sites, were used to study solute movement. In each experiment, water flow was maintained at a quasi steady state by daily irrigations of several hours per irrigation. The irrigations commenced 2 weeks prior to solute application at the sites to create reasonably uniform and moist initial conditions.

For the flux application experiment, a system was designed to allow daily, uniform application of the chemicals over the small plot area $\left(2.25 \mathrm{~m}^{2}\right.$ to $\left.4.0 \mathrm{~m}^{2}\right)$ while the surrounding area received solute-free water at the same rate. Eight covered irrigation frames (or "application systems"), seven of which were $1.5 \mathrm{~m}$ by $1.5 \mathrm{~m}$ and one which was 2.0 $\mathrm{m}$ by $2.0 \mathrm{~m}$, were constructed out of $2.54-\mathrm{cm}$-diameter schedule 40 polyvinyl chloride (PVC), plywood, clear polyethylene sheeting, and 1.27 -cm-diameter plastic drip line tubing. Drip emitters $\left(1.9 \mathrm{~L} \mathrm{~h}^{-1}\right.$ Vortex emitters) were installed on the application systems, 237 in the smaller ones and 400 in the bigger one. Emitter spacing was approximately $10 \mathrm{~cm}$ in a "polymeric diamond" pattern. Each application system was carefully tested and individual emitters selected to maximize application uniformity (see Ellsworth [1989] for details). The application coefficient of uniformity was approximately $95 \%$ for each of the systems. A series of short pulse applications of solution through the drippers over a 4-hour daily period were used to maintain unsaturated flow conditions. The application system was designed so that solute-free water from sprinklers applied over the entire field would land on the covered applicator frame and enter a gutter system which would channel the water approximately $8 \mathrm{~m}$ away from the plot surface. The gutter system was attached to a thin, narrow $(15 \mathrm{~cm}$ width) wall made from 22 gauge, galvanized steel flashing, which defined the plot borders. The flashing was driven $5 \mathrm{~cm}$ vertically into the moist, sandy soil along the plot boundary. A water meter was attached to each drip system to monitor the daily volume of solution applied to the plot surface. Two 880-L tanks were used for the solute solution, with daily mixing of the tank solutions prior to application and periodic sampling to determine the solute concentration in the solution. The tanks had to be refilled several times during the experiments, with slight variability in concentrations be- tween formulations. The mean concentrations in the tanks for all applications were $57.6,39.3$, and $2.7 \mathrm{~mol} \mathrm{~m}^{-3}$ for $\mathrm{Ca}\left(\mathrm{NO}_{3}\right)_{2}, \mathrm{KCl}$, and $\mathrm{H}_{3} \mathrm{BO}_{3}$, respectively. Immediately after each daily irrigation and solute application, the application systems were displaced $8 \mathrm{~m}$ laterally to allow evapotranspiration to occur from the plot surface and from the adjacent areas. Upon completion of the solute application period (approximately 2 weeks) all solute application systems were removed, and subsequent leaching of the entire field was achieved by sprinkler irrigation.

The application system described above created a twodimensional solute flux boundary condition. In addition, a second experiment was designed in which solute was initially resident in the soil. At two sites $(1.5 \times 1.5 \mathrm{~m}$ and $2.0 \times$ $2.0 \mathrm{~m}$ ) the top $5 \mathrm{~cm}$ of soil was carefully excavated, spread out on a plastic surface, and allowed to dry over a 24-hour period while the excavated site was covered to prevent evaporation. The soil was then placed in a portable cement mixer and moistened with water containing solute, applied through a hand-held sprayer, as the cement mixer continuously blended the solution into the soil. After the predetermined volume of solute solution had been applied, water was added until the soil reached a moist, moldable consistency. Upon completion of the water application, the mixing process continued until the soil had been uniformly mixed. The soil was then returned to the excavated site in three equal portions, with uniform packing after each addition using a 20-cm-diameter weighted pipe which was rolled across the surface. Upon completion of the final packing, 8-10 soil cores $(4.8 \mathrm{~cm}$ inside diameter and $5.1 \mathrm{~cm}$ length) were taken from within the plot surface. The soil removed via the sampling was replaced with an equivalent weight of the spiked soil which had been reserved for this purpose. Soil cores were taken surrounding the plot surface also, so that bulk density, moisture content, and the initial solute distribution could be estimated inside and outside the plot surface. Following the initial sampling, the plot surface was moistened with about $0.2 \mathrm{~cm}$ of solute-free water using the hand sprayer, after which the plot was covered with plastic. This procedure was completed in the late afternoon or evening to reduce evaporative water loss. After removal of the plastic cover, daily sprinkler irrigation $(\sim 2 \mathrm{~cm} /$ day $)$ began early the following morning.

\section{Experimental Procedures}

The entire study occurred in two separate phases. The first phase of the study (summer 1987), examined transport on eight of the 10 flux application sites. The second phase occurred between December 1987 and October 1988 on the remaining four sites (two flux application sites and two initial resident distribution sites). During the first phase of the study, the field surface was mowed and plant residues were removed. A $9 \times 9 \mathrm{~m}$ area was rototilled at each of the eight sites to a depth of $8 \mathrm{~cm}$. The field was brought to a steady-state water content with 14 days of sprinkler irrigation immediately prior to solute application. The eight aforementioned application systems were then placed in the center of each rototilled site. With all eight systems installed and the field at a relatively constant water content, solute application commenced.

In order to avoid wind disturbance of sprinkler uniformity, the solute application and irrigations were carried out early 
in the morning. Cups were placed around the plots to provide an estimate of the spatial variability of the sprinkler application as well as an estimate of the daily irrigation rate. The daily coefficient of uniformity for the sprinkler application was usually greater than $90 \%$ around a given plot, yet fieldwide uniformity was approximately $85 \%$ [Ellsworth and Jury, 1991]. The data collected at each site were used to calculate the total applied water for each specific location. Although the fieldwide uniformity was relatively high, a time bias in the application was observed, in which individual sites consistently received greater or lesser amounts of water on a daily basis than the field average.

Potential evapotranspiration (ET) was calculated by the Penman method [Doorenbos and Pruitt, 1975] using daily measurements of solar radiation, wind run, temperature, and relative humidity, from which net applied water (NAW) was calculated as the difference between applied water and ET. During the first phase of the study, solute was applied to each plot over a 2-week period, with approximately $20 \mathrm{~cm}$ of NAW for the seven smaller plots and $30 \mathrm{~cm}$ of NAW for the $2.0 \mathrm{~m}$ by $2.0 \mathrm{~m}$ plot, while the surrounding areas received an equivalent volume of solute-free sprinkler irrigation. It was estimated from the study of Butters et al. [1989] at Etiwanda that the leading edge of the solute front would be approximately 100 to $150 \mathrm{~cm}$ deep after $20 \mathrm{~cm}$ of NAW, which would achieve the objective of having a reasonably cubic shape of the plume at the end of the solute application period. In order to test if this objective was achieved, a $1.5 \mathrm{~m}$ by $1.5 \mathrm{~m}$ plot was destructively sampled the day following the 14-day solute application period (site 2FS). At the other sites, after the solute application, the application systems were removed and all plots subsequently received daily sprinkler irrigation with solute-free water. Each of the remaining six smaller plots were destructively sampled once in pairs after approximately 40,60 , and $80 \mathrm{~cm}$ of NAW. The larger $2.0 \mathrm{~m}$ by $2.0 \mathrm{~m}$ plot was sampled at three times, after approximately 30,55 , and $70 \mathrm{~cm}$ of NAW in order to monitor the leaching pattern of a single plume over time. During each of the first two sampling periods on the large plot, 1.9-cm-thick plywood sheets were placed along the path of the sampling truck. To reduce disturbance of the plume during the first two samplings, holes formed by drilling were backfilled and packed after each sample was taken. Following the sampling sessions, the plot surface was raked to prevent surface ponding of sprinkler irrigation.

The decrease in longitudinal dispersivity between 3.0 and $4.5 \mathrm{~m}$ observed by Butters and Jury [1989] led us to believe that lateral spreading of solute may be significant in this zone. Therefore, we used a relatively sparse sampling grid with holes extending well outside the plot boundaries to be sure that we enclosed the plume completely (figures defining the grids used for each individual sample event are given in the report by Ellsworth and Jury [1991]).

A preliminary analysis of the results from the first phase of the study revealed that the sampling scheme employed provided reasonable mass recovery estimates. However the degree of lateral solute movement was much less than anticipated, and resolution of the horizontal plume boundaries was poor because many of the cores were drilled completely outside of the solute volume. The data also revealed peculiarities in the dispersion process, with vertical plume dimensions initially increasing and then decreasing over time. Further investigation was required to understand the cause of this phenomenon. In addition, the preliminary analysis indicated that the spatial moment estimates obtained from the solute concentrations were sensitive to the interpolation scheme and sampling density.

These results led to the development of the second study phase, examining transport in greater detail on two flux application sites and two initial resident distribution sites. In the second phase, plant residues were carefully removed from each site, leaving the soil surface bare and undisturbed (except for the smaller flux site, which was rototilled prior to placement of the tent). Daily irrigation over a 2-week period was used to create a steady-state initial condition. Two application systems $(1.5 \mathrm{~m}$ by $1.5 \mathrm{~m}$ and $2.0 \mathrm{~m}$ by $2.0 \mathrm{~m}$ ) were subsequently placed in the center of the two flux application sites and used in the same manner as in the first study phase. The two initial resident sites $(1.5 \mathrm{~m}$ by $1.5 \mathrm{~m}$ and $2.0 \mathrm{~m}$ by 2.0 m) were prepared as discussed previously. A denser sampling scheme (relative to the first study phase) was used in the second phase, which provided a greater resolution of the horizontal plume boundaries. After the initial sampling of the two resident concentration plots, the smaller $(1.5 \mathrm{~m})$ plot was destructively sampled once, and the larger $(2.0 \mathrm{~m})$ plot was sampled twice. The $1.5-\mathrm{m}$ flux application site was also destructively sampled once, whereas the $2.0-\mathrm{m}$ flux application site was sampled several times (see Table 1 of Ellsworth and Jury [this issue] for NAW at time of each sampling).

\section{Sampling and Analysis}

During both study phases, experimental sampling procedures were the same. Electrical conductivity measurements of saturation extracts were performed in the field at the time of sampling to ensure that the solute plume was contained within the sample grid boundary. The moment estimates are sensitive to the sample grid density and sample design [McArthur, 1987]. To reduce bias in these estimates, sample grids were placed in a regular, symmetric pattern inside and outside the plot surface.

Between 15 and 37 soil cores were taken at each sampling period using a 6.35-cm-diameter split sampling tube encased in an 18-cm-diameter auger with a Central Mine Equipment model 55 drilling rig. With this equipment, the sample tube is hydraulically driven into the soil without rotating, thereby providing an "undisturbed" core sample. Also, the hole is "cased" with the augers during sampling, which prevents backfill or contamination from occurring. Cores were sectioned into $20-\mathrm{cm}$ depth increments. Each $20-\mathrm{cm}$ segment was thoroughly mixed and subsampled for moisture content. The remaining soil was then placed in a plastic bag, sealed and stored on ice in the field until the end of the drilling day when samples were placed in cold storage $\left(0^{\circ}-4.5^{\circ} \mathrm{C}\right)$ to minimize microbially mediated nitrate transformations. Soil samples remained in cold storage until saturation extracts were performed. In the saturation extract procedures, samples were brought to saturation with deionized water, thoroughly mixed and allowed to equilibrate in the laboratory. A test was performed to ensure that the allotted time was adequate to obtain equilibrium, by examining a subset of samples where the saturated pastes were sealed and allowed to equilibrate for an additional 24 hour period. Chloride and nitrate solution concentrations measured with and without the additional 24 hour period were the same. However, boric acid, also one of the solutes in the study, is adsorbed and 


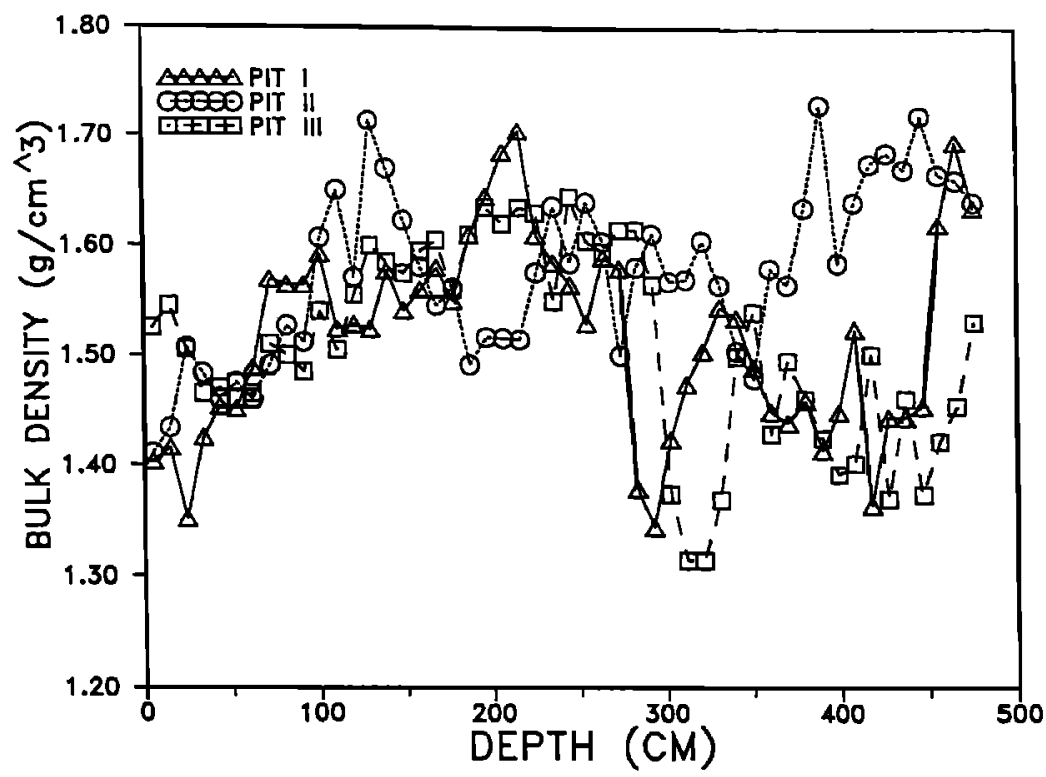

Fig. 2. Bulk density versus depth for all three excavation sites.

enters clay mineral crystal lattice structures via an intracrystalline diffusion process wherein silica is replaced by the borate ion [Jasmund and Linder, 1973]. In this process, the time required to obtain equilibrium between the liquid and solid phases is of the order of years; thus, the boric acid concentration measured by the saturation extract method was not an equilibrium concentration and is termed watersoluble boron. The saturation paste extracts were obtained using buchner suction funnels and number 1 filter paper.

\section{Results AND Discussion}

\section{Field Site Characterization}

The visual observations, bulk density, gravimetric water content, and particle size data obtained from the pit excavations and soil coring provide a semiquantitative physical description of the site. The soil was nearly structureless and visually homogeneous from the surface to a depth of $2.5 \mathrm{~m}$. Below this depth, the soil had a subangular blocky structure. Several old grape roots were found, approximately $0.5 \mathrm{~cm}$ in diameter, which penetrated to depths in excess of $3.0 \mathrm{~m}$. Very little gravel or coarse material was found in pits I and III, which were located in the central part of the field (see Figure 1). However, greater quantities of gravel were observed in the pit located at the western part of the field. The soil is thought to be part of an alluvial fan. The visual similarities in the vertical profiles of the three pits support this assumption. It appeared from these observations that the field was relatively uniform within a given horizontal layer or depth, with a large degree of vertical variability between different layers. Figure 2 shows the bulk density as a function of depth for the three pits. The observed bulk

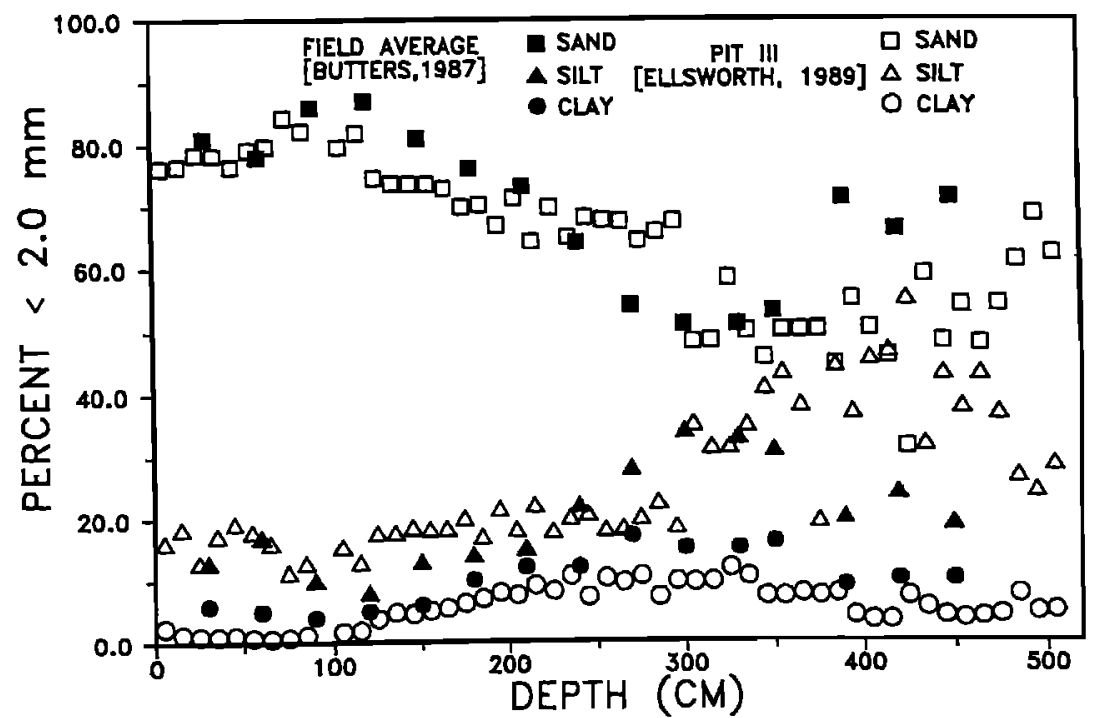

Fig. 3. Particle size distribution from field average sampling [Butters, 1987] and from pit III (this study). 


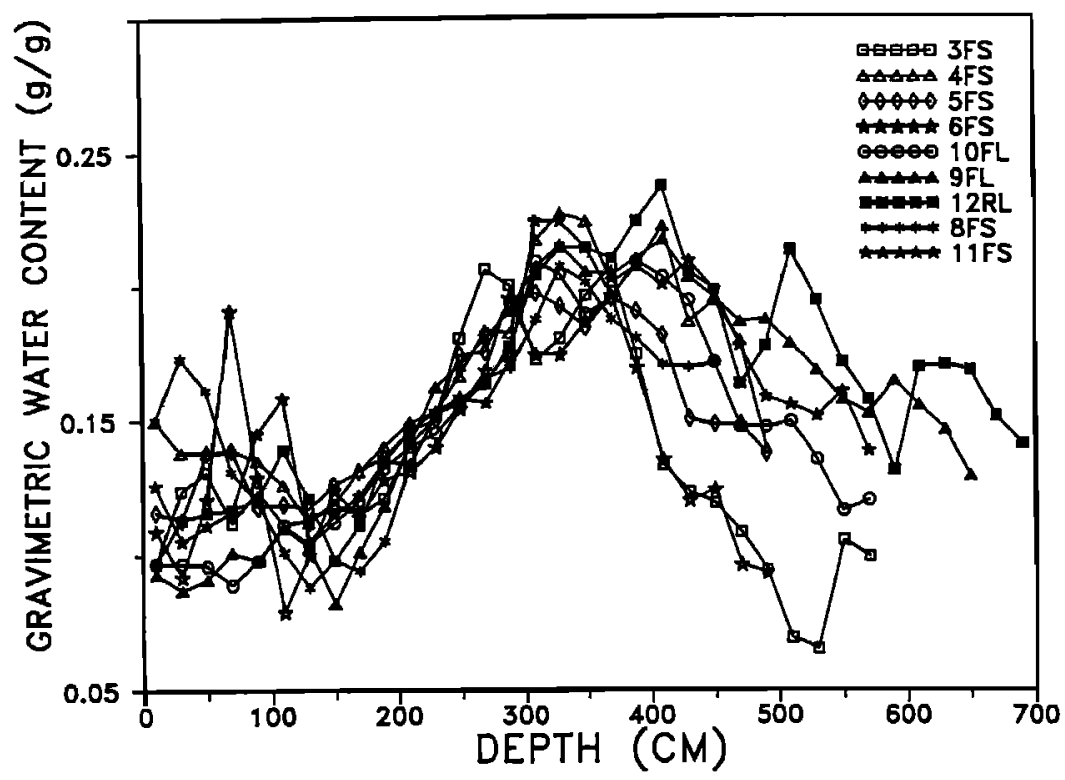

Fig. 4. Steady-state gravimetric water content profile for nine of the 12 sites (data for sites $2 \mathrm{FS}$ and $7 \mathrm{RS}$ are given in Figure $6 a$, and IFS was omitted as a consequence of its position over a buried water line).

density profiles are quite similar between the surface and a depth of $2.8 \mathrm{~m}$. Below this depth, the data for pit II deviate considerably from the other two sites.

Butters et al. [1989] reported the results of a particle size analysis performed on field-averaged samples taken randomly over the field and mixed into composite $30-\mathrm{cm}$ layers prior to analysis. His results and the particle size analysis for the local samples taken from pit III are presented in Figure 3. The similarity between his data and that for pit III provides further evidence of the high degree of horizontal homogeneity and vertical heterogeneity in the field. The gravimetric water content profiles, determined as the average in the individual soil cores from each sampling at nine of the sites, are given in Figure 4. (The data for site 1FS were omitted from this figure as this site was inadvertently located above a preexisting $1.8 \mathrm{~m}$ deep, $35 \mathrm{~cm}$ diameter, water line. The data for the two remaining sites are presented in Figure $6 a$.) Figure 4 also supports the conclusion of a high degree of horizontal uniformity and vertical variability within the field, especially within $4.0 \mathrm{~m}$ of the soil surface. The bulk density and gravimetric water content data additionally indicate that the horizontal layers have a slight slope in the southern direction. This can be seen in Figures $5 a$ and $5 b$, in which bulk density data from pits I and III are shown together, with the data for pit I in Figure $5 b$ displaced downward by $20 \mathrm{~cm}$ (pit I is $\sim 25 \mathrm{~m}$ north of pit III). Figures $6 a$ and $6 b$ demonstrate this same relationship from the steady-state gravimetric water content for two sites which were separated by

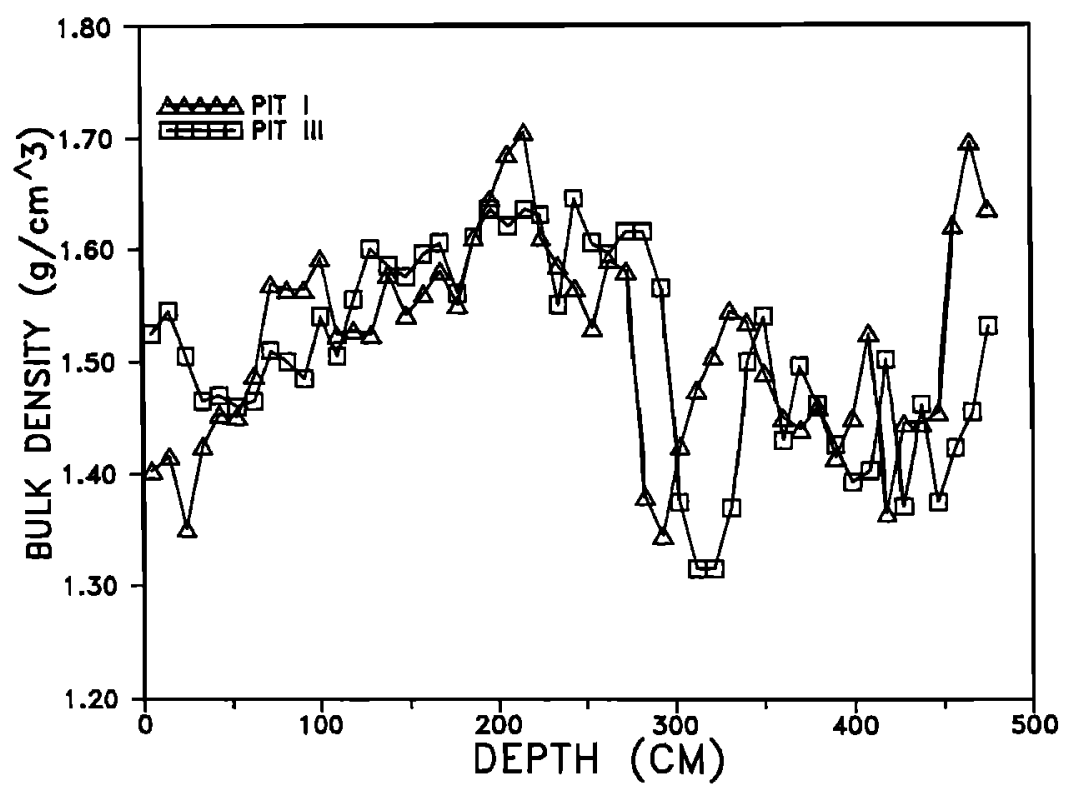

Fig. 5a. Bulk density versus depth for pits I and III. 


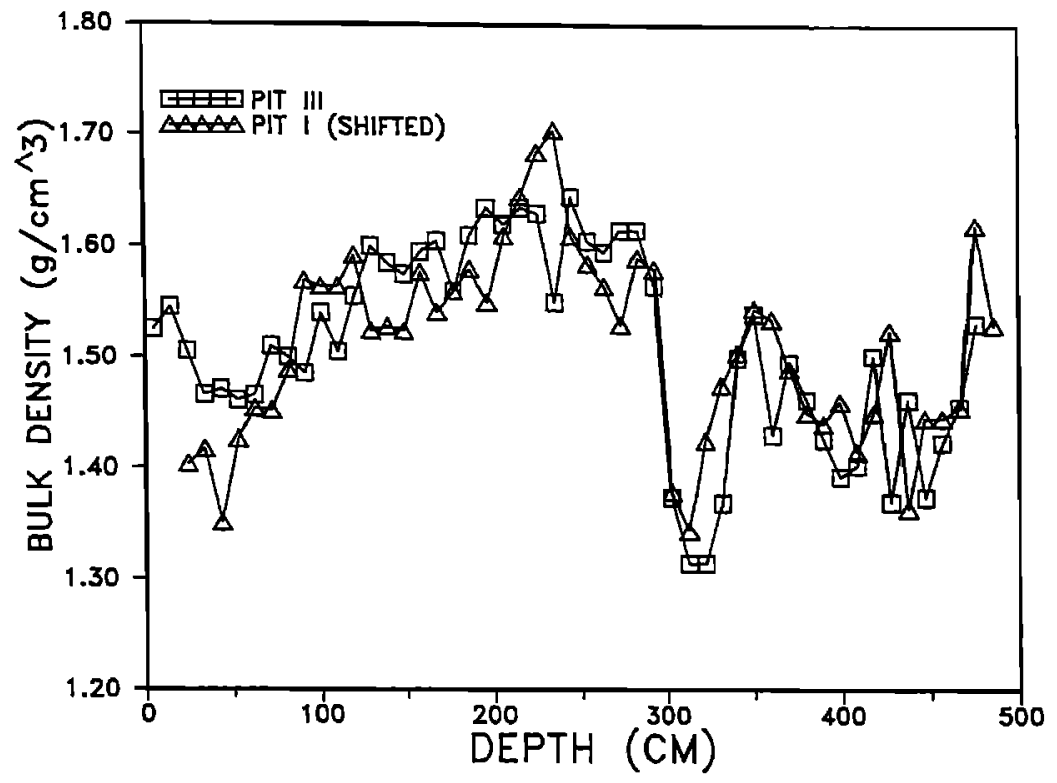

Fig. 5b. Bulk density versus depth for pits I and III, with data from pit I (northernmost pit) displaced $20 \mathrm{~cm}$ downward.

approximately $25 \mathrm{~m}$ in the north-south direction (plots $2 \mathrm{FS}$ and $7 \mathrm{RS}$, defined in Figure 1) with Figure $6 b$ showing the northern plot data shifted $20 \mathrm{~cm}$ downward.

\section{Data Analysis}

The soil coring and sampling procedure provided between 293 and 1016 localized measurements of solute concentration at each site, which produced a three-dimensional, discrete data set with each measurement representing an average resident solute concentration in a $200 \mathrm{~cm}^{3}$ volume of soil at the time of sampling. Figure 7 illustrates the chloride depth profiles of each core obtained from a $1.5 \times 1.5 \mathrm{~m}$ flux application site (8FS, defined in Figure 1) which was destructively sampled once after $49.6 \mathrm{~cm}$ of NAW had been applied ( $19.2 \mathrm{~cm}$ with the solute and $30.4 \mathrm{~cm}$ by leaching afterward).

One of the purposes in using two tracers such as chloride

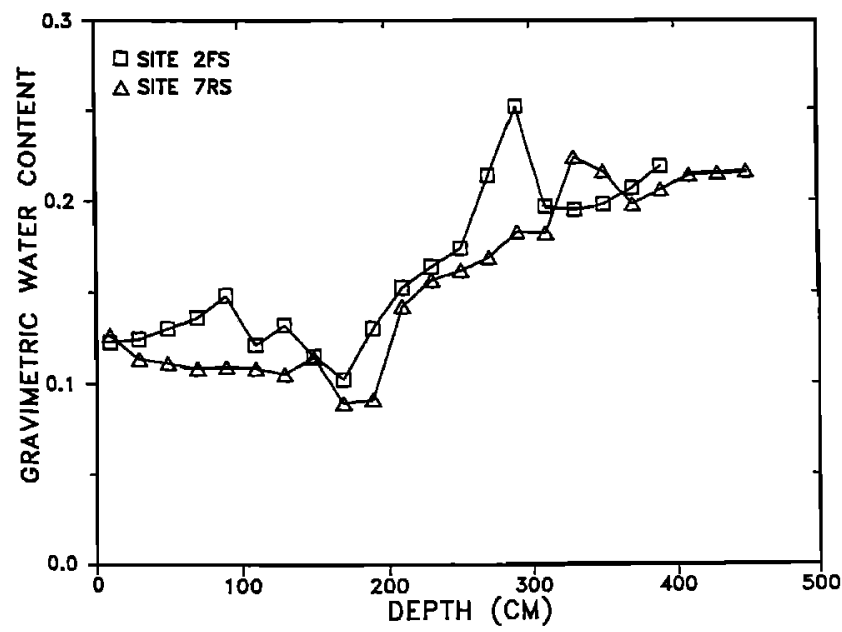

Fig. 6a. Steady-state, gravimetric water content profiles for plots $2 \mathrm{FS}$ and $7 \mathrm{RS}$, with site $2 \mathrm{FS}$ located approximately $25 \mathrm{~m}$ north of 7RS. and nitrate was to provide a measure of experimental quality control. To examine the variability in the data resulting from sample handling and analytical error, a linear regression equation was used to predict the concentration of one of the two "water tracers" from the other. We recognize that sample handling and analytical error are not the only processes which could result in variability between measured nitrate and chloride concentrations in the same soil sample (for example, the following discussion of mass balance suggests that nitrate was not a conservative tracer). However, we believe experimental error would be the primary source of variability between the two solutes. Table 1 contains the square of the correlation coefficient $\left(R^{2}\right)$ for all sample events and depths during the first study phase (except the 0-20 cm depth, where residual nitrate concentration was always greater than chloride). Mislabeling samples, equipment malfunction and other human errors would

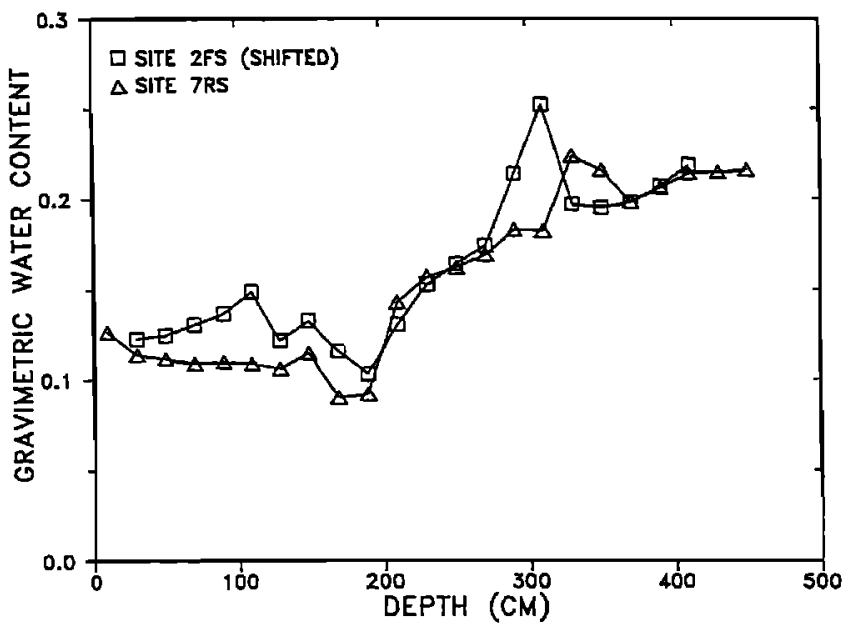

Fig. $6 b$. Same as Figure $6 a$ except data for site 2FS (located $25 \mathrm{~m}$ north of 7RS) are shifted vertically $20 \mathrm{~cm}$. 


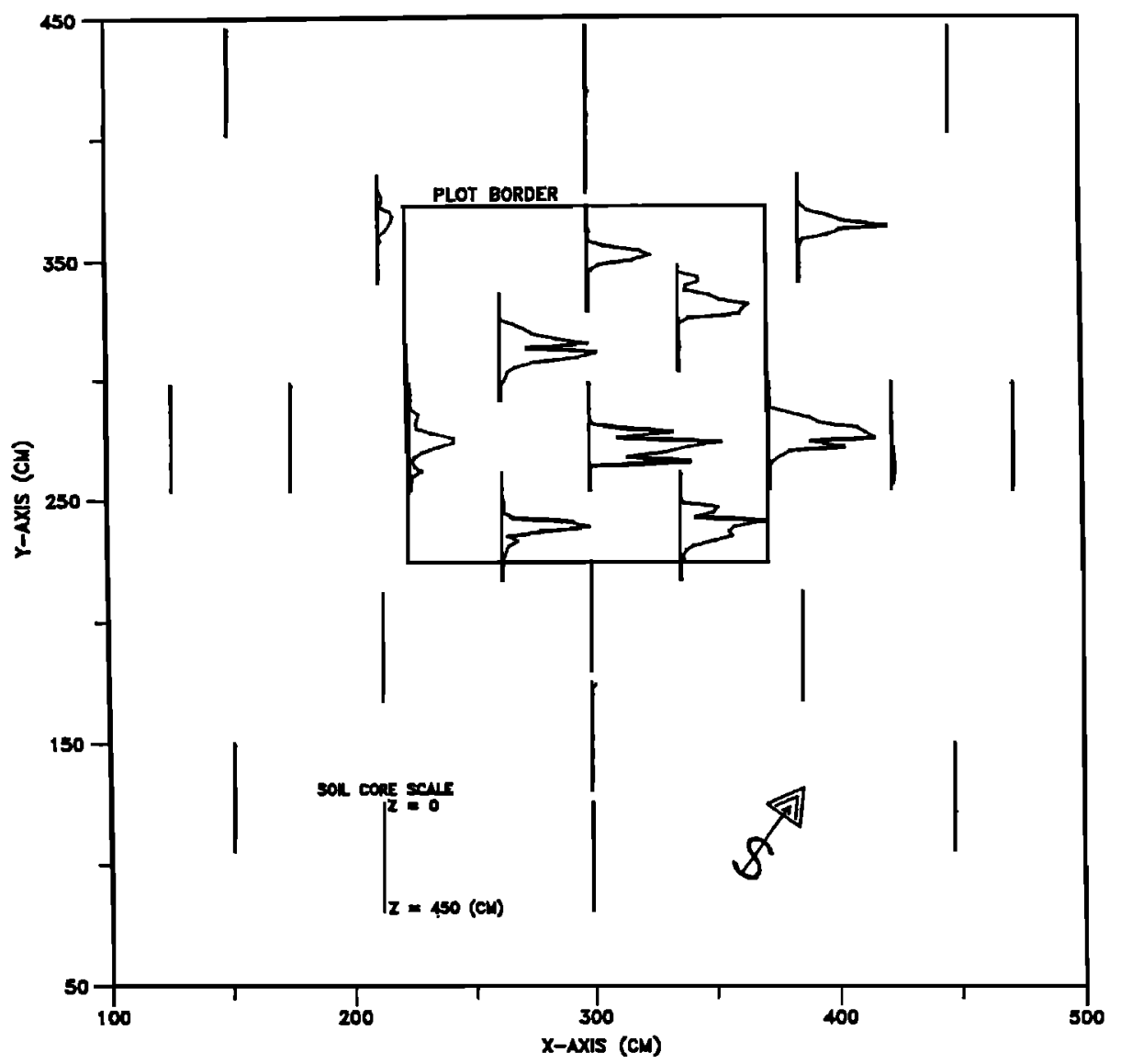

Fig. 7. Chloride distribution in individual soil cores taken after $49.6 \mathrm{~cm}$ of net applied water on a $1.5-\mathrm{m}$ flux application site (8FS).

reduce the computed $R^{2}$. The relatively large $R^{2}$ values observed provide a measure of assurance that experimental errors were minimal, especially since part of the variability evident in the $R^{2}$ values is probably a consequence of nitrate transformations.

The method of spatial moments was chosen to analyze and interpret the transport phenomena. There were several reasons for this choice. First, the method of moments does not assume anything a priori about the transport process and is thus nonparametric and model independent. However, the moments can be conveniently used to determine modeldependent parameters. Secondly, the method of moments

TABLE 1. Correlation Coefficients Between $\mathrm{NO}_{3}$ and $\mathrm{Cl}^{-}$ Concentrations Measured in the Different Plots During the First Study Phase

\begin{tabular}{cl}
\hline Sample & $R^{2}$ \\
\hline 1FS & 0.98 \\
2FS & 0.93 \\
3FS & 0.98 \\
4FS & 0.98 \\
SFS & 0.98 \\
6FS & 0.99 \\
11FS & 0.99 \\
10FLa & 0.98 \\
10FLb & 0.94 \\
10FLc & 0.98 \\
\hline
\end{tabular}

provides a physical characterization of the plume which is conceptually appealing and easy to visualize. Furthermore, the spatial moments are commonly used in the literature for characterizing transport processes, from both applied and theoretical perspectives [Bresler and Dagan, 1981; Freyberg, 1986; Dagan, 1987; Sposito and Barry, 1987]. The spatial moments are defined in an analogous manner to the statistical moments of probability theory [DeGroot, 1986]. The absolute zeroth, first and second spatial moments are defined by the following integral expressions:

$$
M_{0}(t)=\int_{V} \theta_{v} C\left(X_{1}, X_{2}, X_{3}, t\right) d V
$$

$M_{k}(t)=\frac{1}{M_{0}(t)} \int_{V} \theta_{v} X_{k} C\left(X_{1}, X_{2}, X_{3}, t\right) d V$

$$
k=1,2 \text {, or } 3
$$

$$
M_{k h}(t)=\frac{1}{M_{0}(t)} \int_{V} \theta_{v} X_{k} X_{h} C\left(X_{1}, X_{2}, X_{3}, t\right) d V
$$

$$
k, h=1,2 \text {, or } 3
$$

where $M_{0}(t)$ is the total mass of solute within the soil volume $V$ at time $t ; M_{x}(t), M_{y}(t), M_{z}(t)$ is the position of the center of mass of the plume at time $t ; M_{k h}(t)-$ 


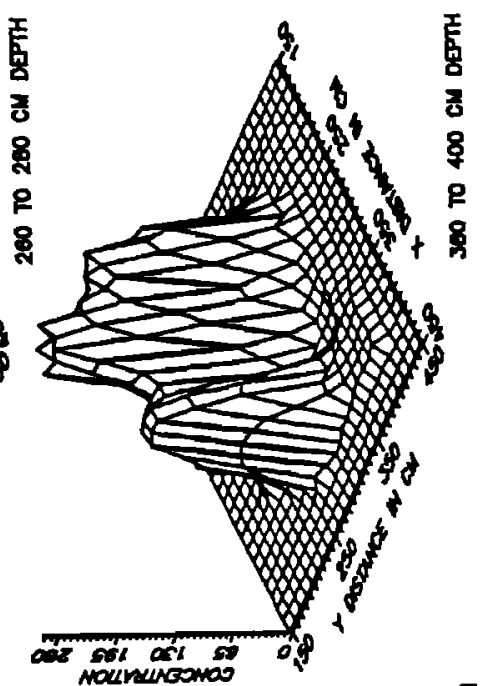

$\mathbf{5}$
8
3
8
$\frac{7}{2}$
8
8
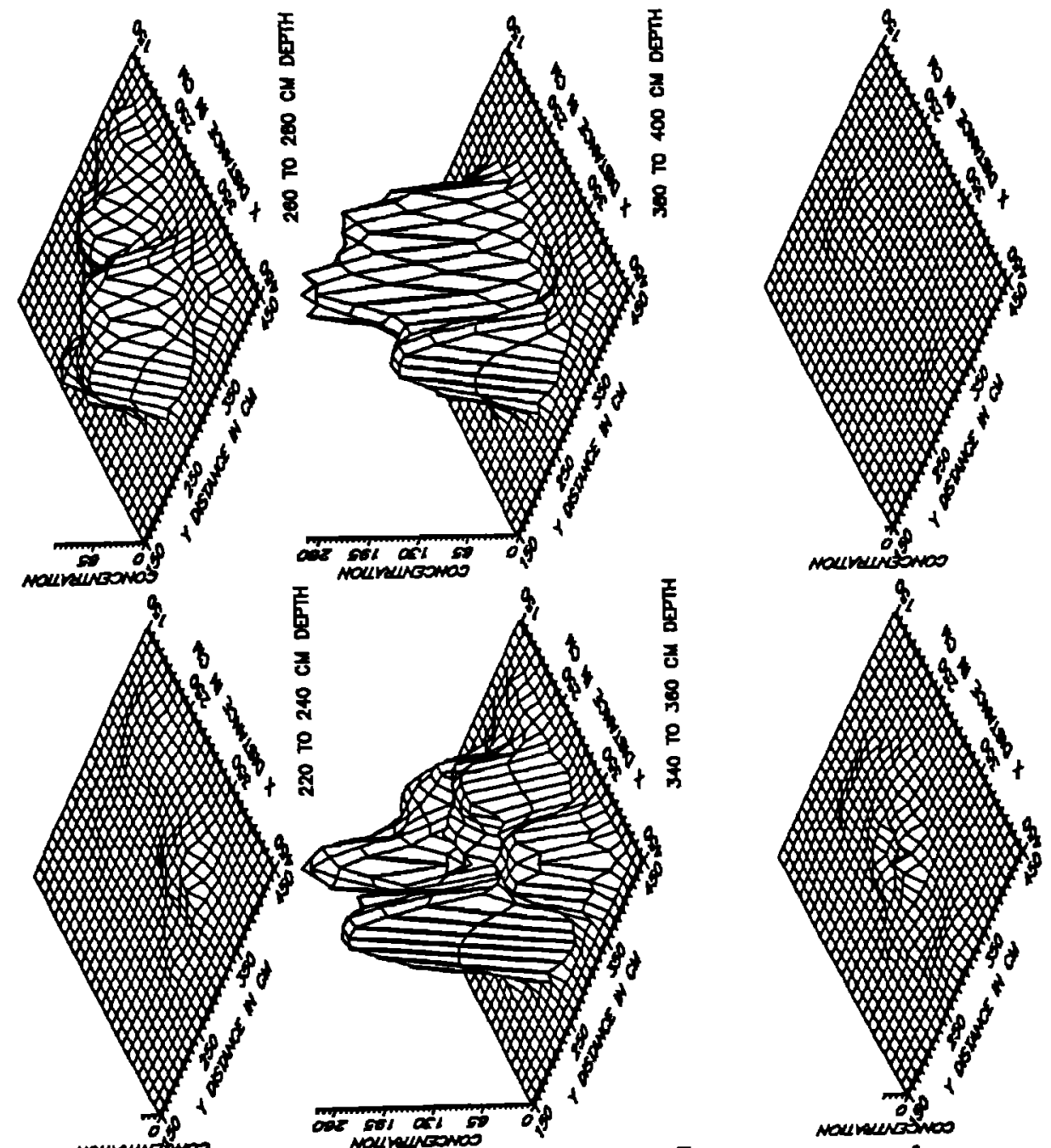

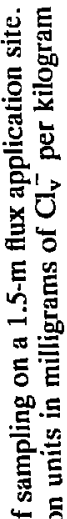
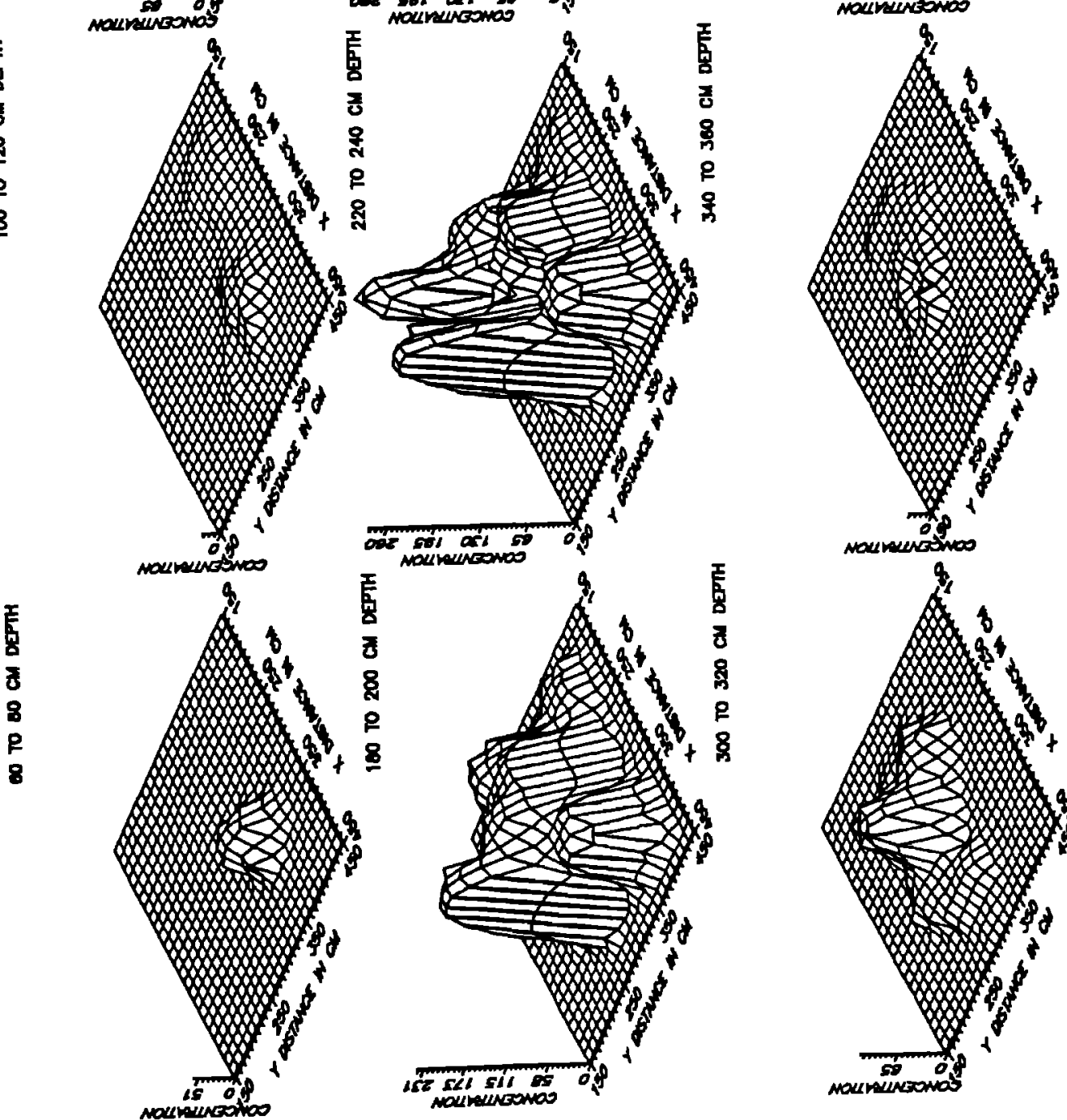

焉
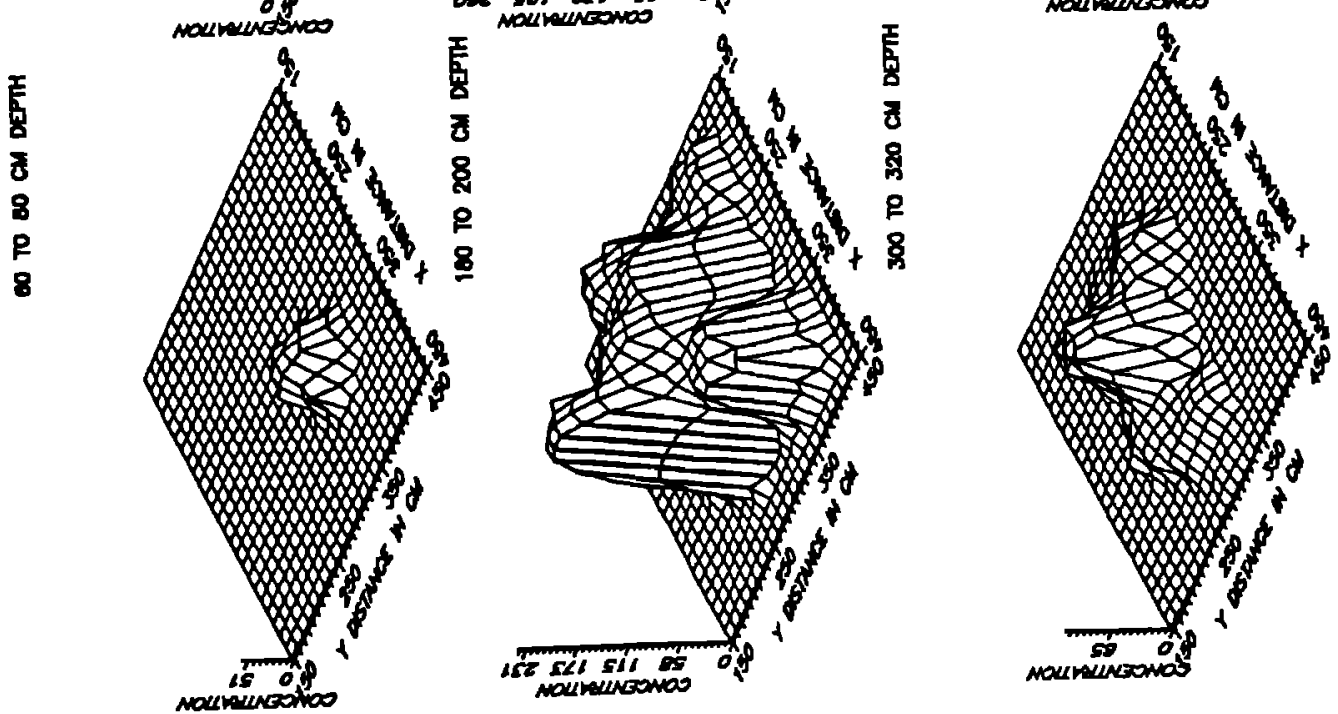

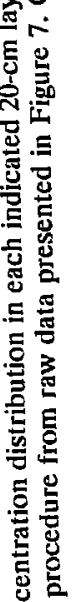

就

능

흘롤

尊至

䆓爮宫

$\infty$ 它

诖憵 


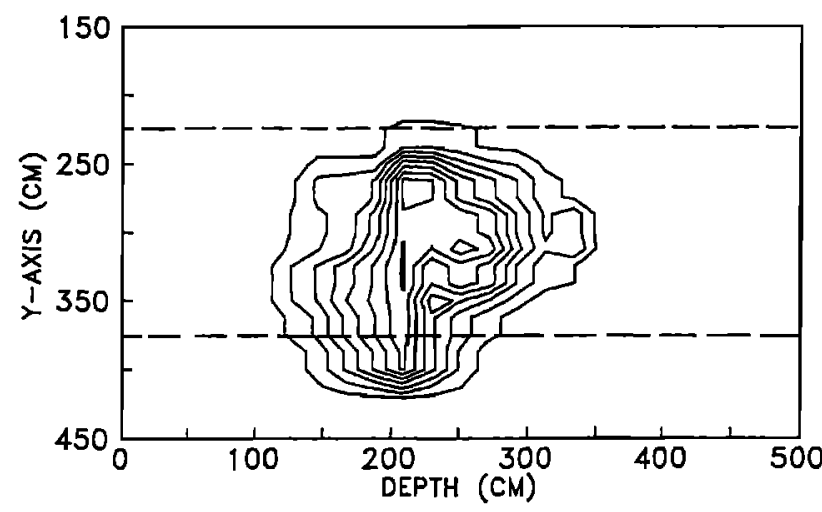

Fig. 9a. Normalized, $x$ axis averaged, two-dimensional perspective of a chloride plume after $49.6 \mathrm{~cm}$ of NAW (plot 8FS).

$M_{k}(t) M_{h}(t)$ is the spatial covariance of the concentration about the center of mass at time $t ; \theta_{v}$ is the volumetric water content; and $V$ is the volume enclosing the plume (the second central moments are discussed elsewhere (for example, see Ellsworth and Jury [1991, this issue])). As can be seen in (1)-(3), the calculation of the moments requires a three-dimensional integration over the sampled soil volume. Therefore, the solute concentration at each point within the soil must be estimated either explicitly or implicitly from the raw data.

The procedure chosen for computation of the moments was a three-dimensional interpolation of the data using an inverse distance weighting scheme. As pointed out by Barry et al. [1988], the calculated moments are sensitive to the weighting factor used in the interpolation procedure. Crossvalidation [Geisser, 1975] was the criteria used to select the weighting factor in the present study. The sensitivity of the estimated moments to the interpolation scheme is discussed in Appendix A of Ellsworth and Jury [1991], which also provides a thorough explanation of the interpolation method we used in this study. In general, the calculated center of mass of the plumes was relatively insensitive, mass recovery somewhat more sensitive, and plume spatial covariance the most sensitive to the interpolation scheme used.

The primary properties of this interpolation scheme are that it is an exact interpolant, that it provides a continuous functional representation of the solute concentration, and that predicted concentration values are bounded by the maximum and minimum observed values [Crain and Bhattacharyya, 1967]. This interpolation scheme was used to create a dense, regularly spaced, three-dimensional concentration grid from the raw data of each sampling, with an interpolated grid containing approximately 30,000 grid nodes. By creating such a dense grid, the method of integration used for (1)-(3) has only a minimal influence on the moment estimates and bias in the results arises primarily from the density and location of the original data points, and from the interpolation procedure.

The interpolation scheme provides a convenient method for visualizing the solute plumes. The densely spaced grids can be used to generate one-, two-, and three-dimensional perspectives of the plumes at the time of sampling. Since the procedure is an exact interpolant, the three-dimensional graphics so created provide a resolution of the plumes at the scale defined by the sampling density. Each of the nine subfigures in Figure 8 (created using the interpolation grids from the raw data in Figure 7) illustrate the chloride mass distribution in the horizontal plane for a series of $20-\mathrm{cm}$-thick vertical layers from plot 8FS. Figures $9 a$ and $9 b$ show normalized, two-dimensional perspectives of this plume in the $Y Z$ and $X Z$ planes generated from the concentration grids by integration of the spatial solute distribution over the appropriate axis. At the time of sampling, the plume extended laterally approximately $30-40 \mathrm{~cm}$ from the plot borders. The center of the plume was at a depth of $220 \mathrm{~cm}$. Some irregularity in the spreading process is apparent in comparing Figures $9 a$ and $9 b$.

A more quantitative method for examining the plumes is possible with the moment estimates. In the flux application experiment, the mass applied to each plot was measured independently using water flow meters and analysis of the applied solution concentrations. However, for the two resident distribution sites, the estimates of the mass applied were calculated from the mass mixed with soil in the mixer and also from that measured in the surface samples taken at the commencement of leaching. These two estimates were significantly different. As a result of this uncertainty in the applied mass for the resident distribution sites, a quantitative comparison between the zeroth spatial moment estimate and the applied mass was thought to only be valid for the flux experiment.

The comparison between the applied mass and mass recovery estimate provides a measure of the success of the experimental technique. The ratios of the estimated zeroth spatial moment to the applied mass for 12 of the 14 sample events in the flux experiment are presented in Figure 10 for both chloride and nitrate. The results for sites IFS and 8FS were omitted from this figure because, as mentioned previously, site 1FS was situated above a preexisting water line, and mass recovery was anomalous because the plot could not be sampled adequately. Also, at site $8 \mathrm{FS}$, the solution samples taken to determine the concentration of the applied solute were inadvertently disposed of in the laboratory prior to analysis.

Since chloride does not transform, adsorb, or volatilize significantly, the entire mass of applied chloride must be located in the soil solution. Nitrate, although also residing entirely in solution, is subject to a variety of transformations in the soil. The processes which are most relevant to this study are losses due to denitrification (as a consequence of

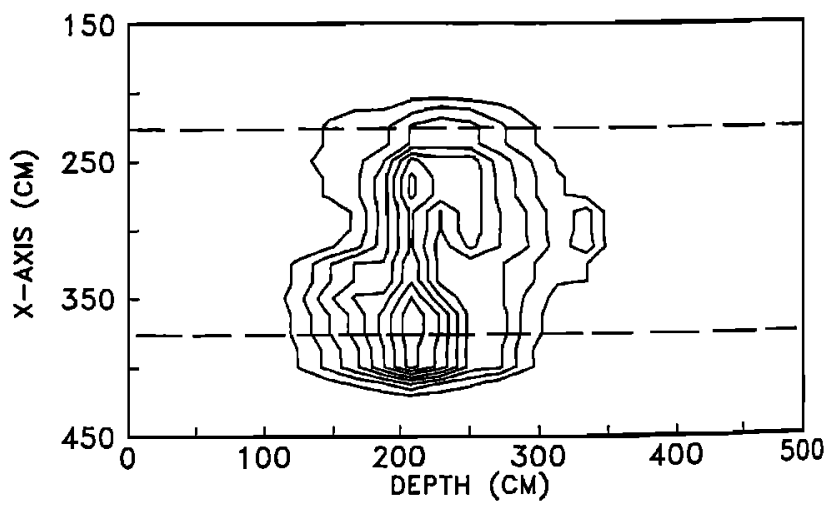

Fig. $9 b$. Normalized, $y$ axis averaged, two-dimensional perspective of a chloride plume after $49.6 \mathrm{~cm}$ of NAW (plot 8FS). 


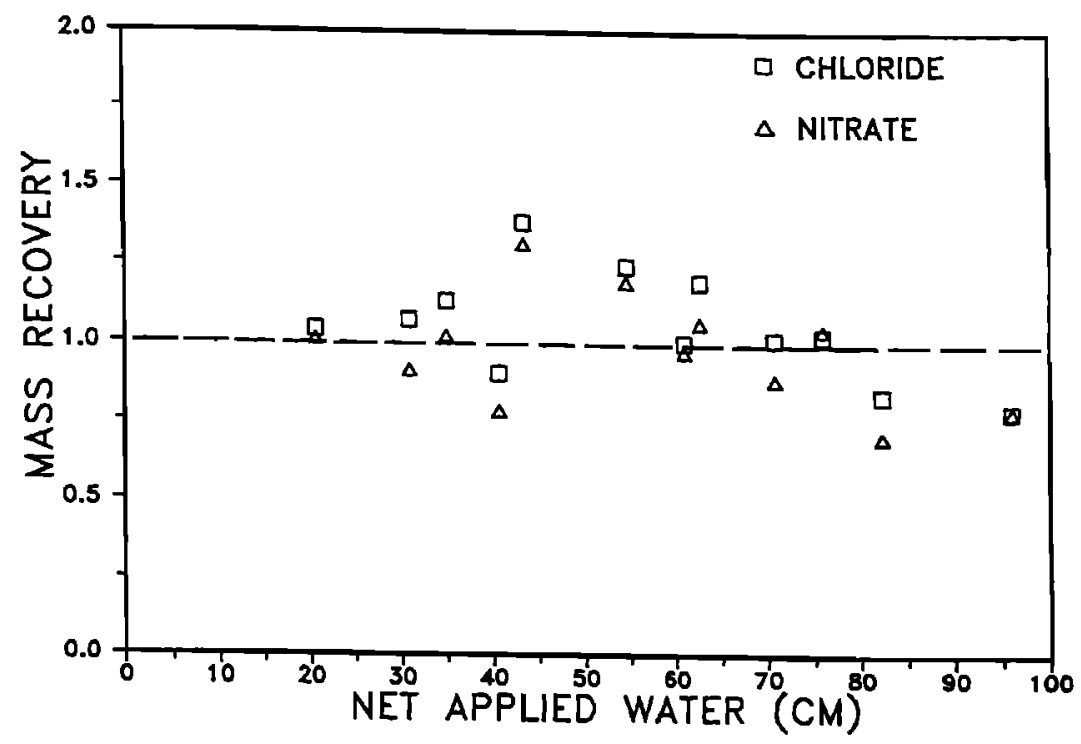

Fig. 10. Chloride and nitrate mass recovery, flux application experiment.

the daily irrigation regime) which may occur throughout the soil profile, and additions/sinks through microbial decomposition/uptake of organic matter. Soil samples taken during the experiment showed significantly greater residual nitrate concentrations in the top $20 \mathrm{~cm}$ of the soil profile. The complex reactions which influence the form of nitrogen in the soil thus result in uncertainty as to whether the mass of nitrate applied was conserved. Comparison of mass estimates for each sampling in the flux experiment showed that the percent mass of nitrate recovered was less than, or equal to, that of chloride except for one sample event in which it was $2 \%$ higher (Figure 10). This suggests that the applied mass of nitrate was not conserved, although in most cases the differences in recovery of the two chemicals are small.

There also appears to be a decrease in the amount of mass recovered for both solutes at the two longest sampling times (NAW). The significance of this decrease is not clear and may simply be a reflection of the interaction between the interpolation scheme and the measured resident concentrations, which were relatively lower at these last samplings. The decrease in mass may also be a reflection of the sampling methodology. As the sampled soil volume increased with time, the number of samples collected per unit volume of soil was consequently less, possibly resulting in a lower recovered mass.

Figure 11 summarizes the percent mass of water-soluble $B$ (100 times recovered mass fraction) from the soil solution as a function of NAW for the 1.5 -m plots in experimental phase 1. In contrast to the other solutes, B recovery was significantly less than the amount applied and decreased sharply with time. Boron is thought to be adsorbed as an inorganic oxyanion $\left(\mathrm{B}(\mathrm{OH})_{4}^{-}\right.$(aq)) via a two-step ligand exchange reaction, forming an inner-sphere complex with inorganic soil surface hydroxyl groups [Sposito, 1984]. Since boron

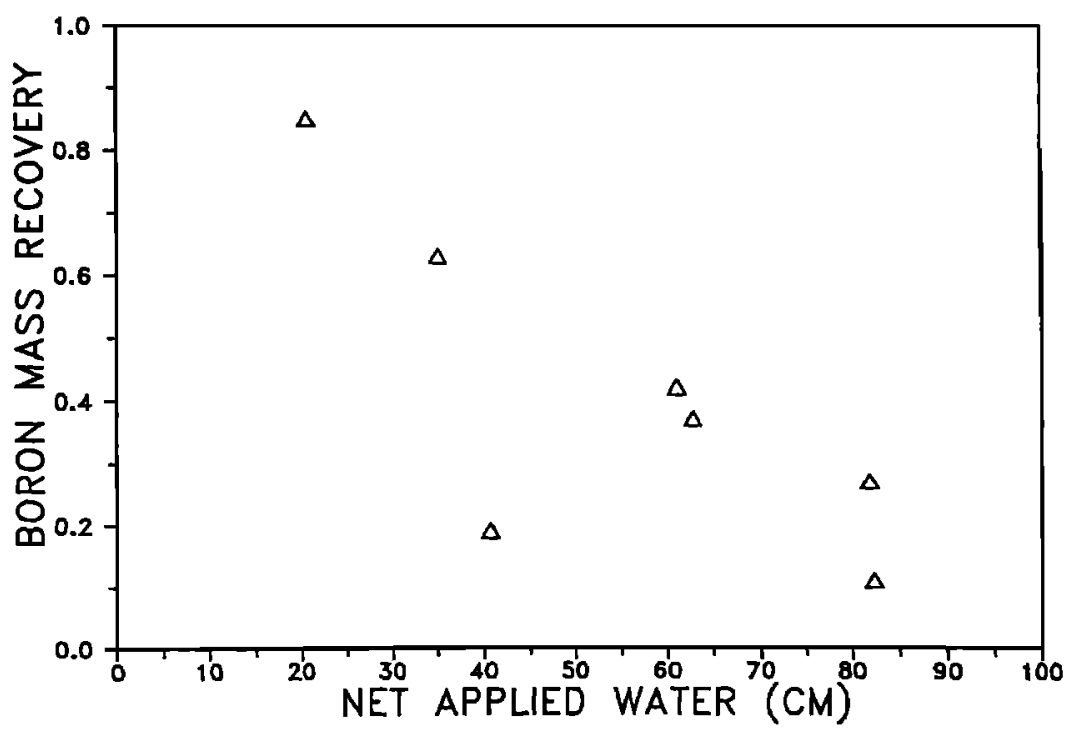

Fig. 11. Water-soluble boron mass recovery, 1.5-m plots, first study phase. 


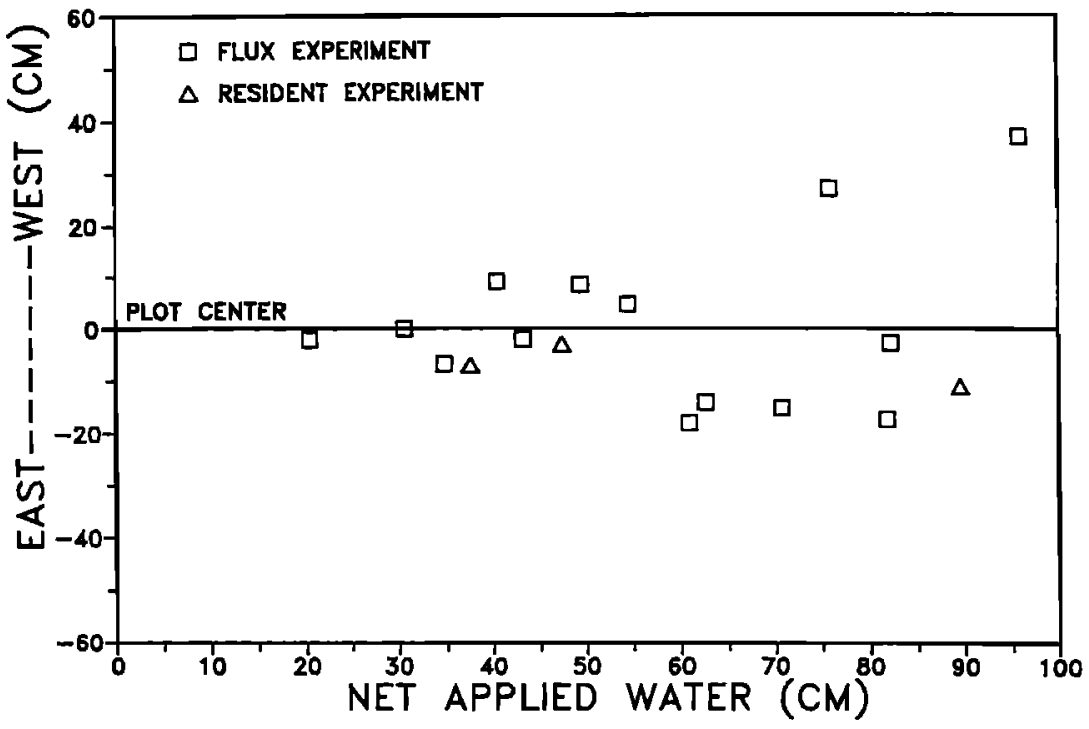

Fig. 12a. East/west deviation of plume center of mass from plot center as a function of NAW (all sites).

adsorption can be appreciable in alkaline soils such as that found in this field [Goldberg and Glaubig, 1986], and as adsorbed $B$ is resistant to extraction from water-saturated pastes, it was expected that the water-soluble fraction would represent only part of the applied $B$.

Figure 12 shows the location of the chloride plume center of mass for all sample events in both the flux and resident distribution experiments, relative to the center of each plot. The deviation of the plume center of mass in an easterly or westerly direction from the location of the plot center appears to be random with increasing variability as a function of NAW (Figure 12a). However, there appears to be a trend in the deviation of the plumes from the center of the plots in a southerly direction, as shown in Figure $12 b$. There is also much greater variability in the deviations about the plot center in a northerly or southerly direction than in an easterly or westerly direction. The observed net drift of the

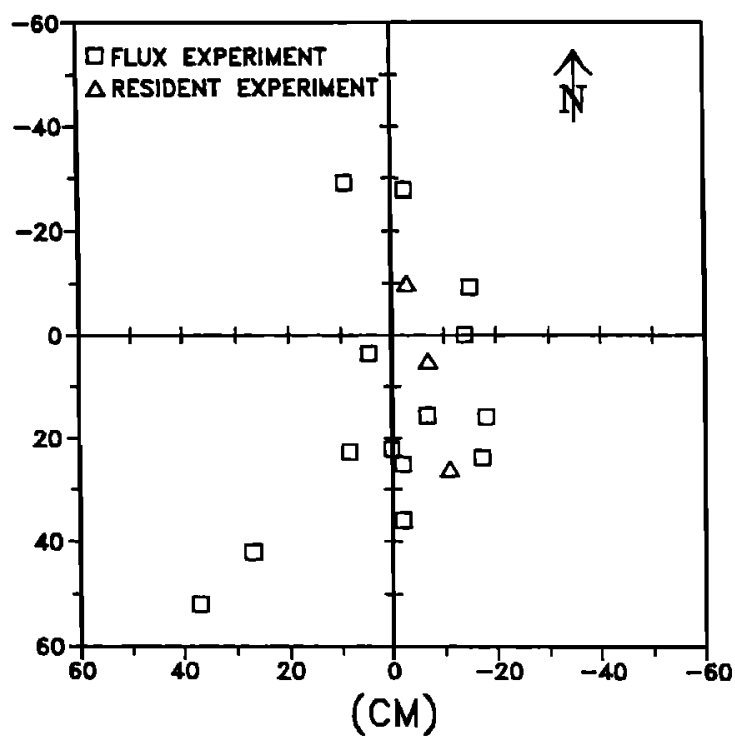

Fig. 12b. Horizontal location of plume center of mass relative to plot center. plumes to the south is consistent with the slight slope detected from the analysis of water content and bulk density (Figures 5 and 6).

Figure 13 displays the vertical position of the center of mass of chloride and boron as a function of NAW for nine of the 10 sample events during the first experimental phase (the plot which was directly over the main line was omitted). It is apparent that the water-soluble boron fraction was signifcantly retarded relative to chloride. However, of greater interest in this figure is the consistency in the observed transport process between the different plots which were located throughout the field (Figure 1). There appears to be a unique relationship for the entire field between vertical position of the center of mass of the different plumes and NAW for chloride, and a second one for water-soluble boron, even though boron transport was significantly retarded relative to chloride.

If the ordinate of this graph were time, the slope of the depth of the center of mass versus time curve would define a mean solute velocity. In a truly steady-state experiment, the only difference between a graph of the center of mass versus time or versus NAW would be the scale of the ordinate axis. However, as a result of the daily variations in evaporative water flux, applied surface flux, and interruption of daily irrigation on multiply sampled plots during sampling periods, only "quasi" steady-state conditions were realized during the experiment. Thus, NAW is a more direct factor than time in governing the transport process.

The observation that the soil properties which determine the mean solute "velocity" (or location of the plume center of mass as a function of NAW) are relatively uniform between the various plots agrees with the field characterization study, which showed a relatively high degree of horizontal homogeneity in texture, structure, bulk density, and gravimetric water content despite a large degree of vertical variability in these same properties. Therefore, we used the field-averaged volumetric water content, $\theta_{v}(z)$ (obtained for each 20 -cm depth increment as the product of the average bulk density from the three pits and the mean gravimetric water content for all plots), to predict the vertical position of 


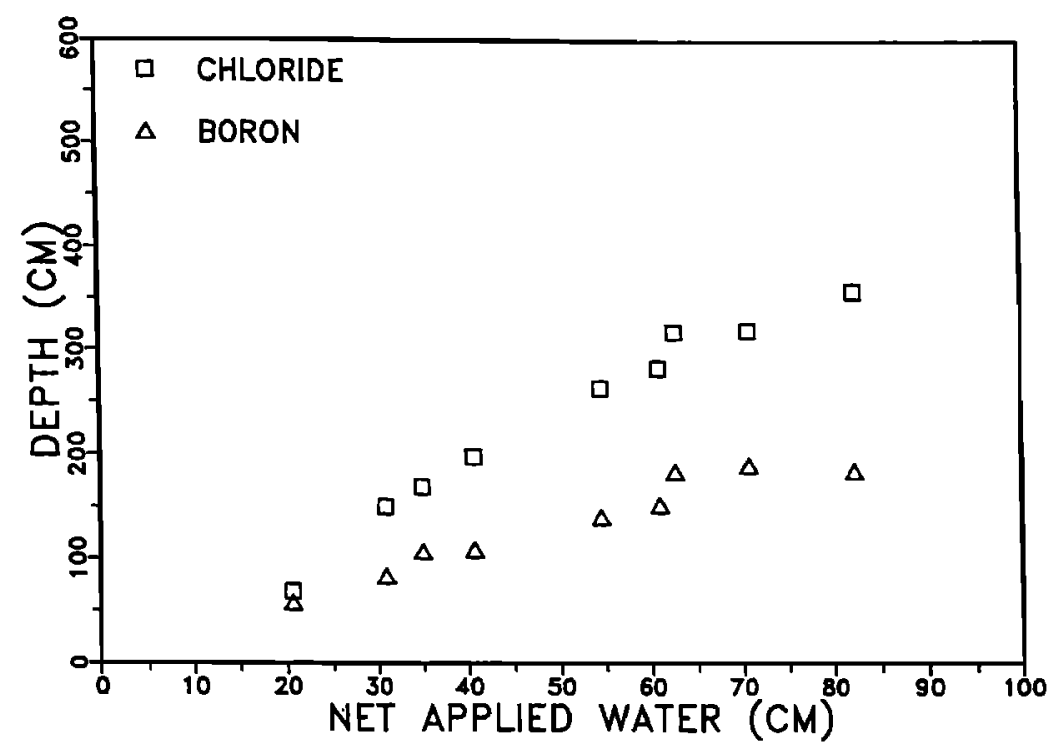

Fig. 13. Chloride and water-soluble boron plume center of mass versus NAW (study phase 1).

the chloride plume center of mass using the piston flow model. This model assumes that all of the soil solution is replaced by the infiltrating solute front. Thus, the depth of the plume center of mass, $Z_{\mathrm{cm}}$, after a total net amount of water (NAW) has been applied is predicted from the piston flow model by

$$
N A W_{c m} \equiv N A W-\frac{N A W_{0}}{2}=\int_{Z_{0}}^{Z_{c m}} \theta_{v}(s) d s
$$

where $N A W_{0}$ is the centimeters of net applied solute solution $\left(N A W_{0}=0.75 \mathrm{~cm}\right.$ for the initial resident distribution experiment), $s$ is a dummy integration variable, and $Z_{0}$ is 0 for plumes created with flux application and $2.5 \mathrm{~cm}$ for the resident experiment.

Figure $14 a$ shows the $Z_{c m}\left(N A W_{c m}\right)$ line predicted from (4), along with the measured values for both the flux and resident experiments. The slopes of the measured and predicted values are very nearly the same; however, the piston

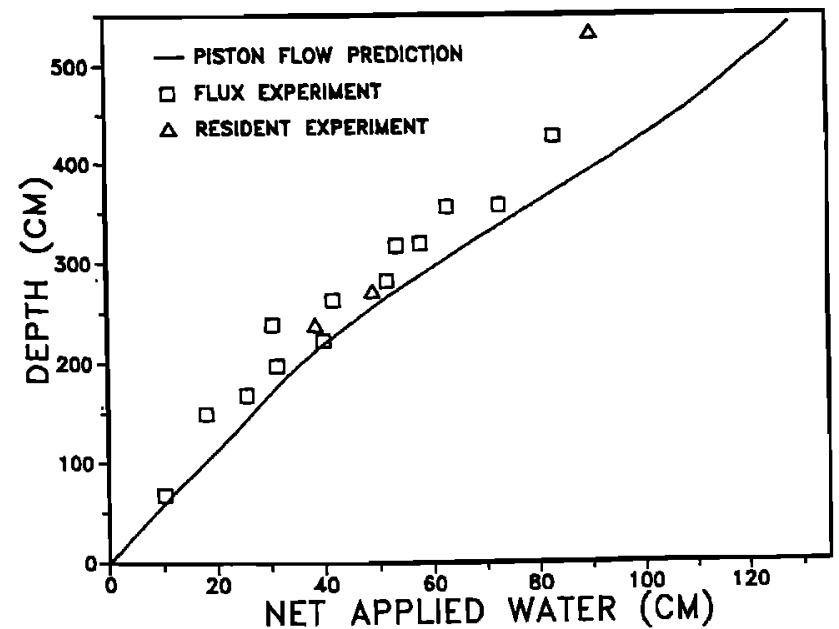

Fig. 14a. Measured and piston flow-predicted chloride plume center of mass as a function of NAW. flow model consistently underpredicts the depth of the center of mass. It also is apparent that the discrepancy is greater for the flux experiment. Two experimental factors which contribute to this underprediction are the time delay between the final irrigation and the time of sampling, and also the use of drip emitters for solute application in the flux experiment. The time of sampling at each site was between 1 and 3 days after the last irrigation, except for 9FLc and $12 R L b$ which were the final two sampling events of the experiments and were sampled $1,2,5$, and 6 days after the last irrigation and 7,8 , and 9 days, respectively, as a consequence of breakage in the sprinkler system. From 14a, the influence of the time delay in sampling is evident in examining the large underpredictions for 9FLc and $12 \mathrm{RLb}$ (83.2 and $89.6 \mathrm{~cm} \mathrm{NAW_{cm }}$, respectively).

The greater underprediction for the flux experiment than for the resident experiment suggests that water applied through the dripper system may have bypassed part of the

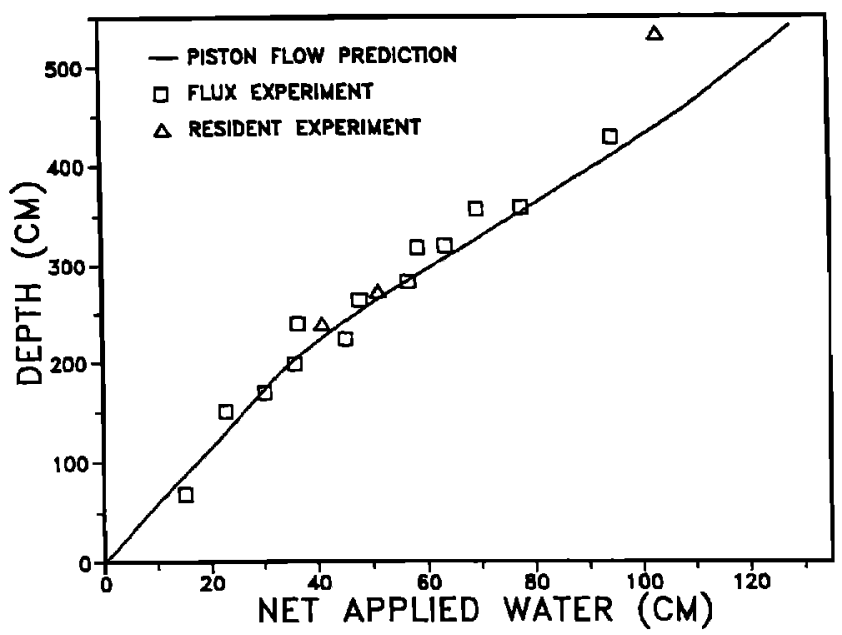

Fig. 14b. Measured and piston flow-predicted chloride plume center of mass as a function of NAW (with correction for time delay of sampling and dripper bypass). 
soil volume near the surface. To test this hypothesis, a solution containing a water-soluble dye (amine red) was added to the soil through the dripper system and the underlying soil subsequently excavated. Dye was found directly below each dripper in a soil volume shaped like an inverted cone. The dye patterns from adjacent drippers $(10 \mathrm{~cm}$ spacing) were observed to intercept each other at a depth of roughly $40 \mathrm{~cm}$, implying that during solute application, approximately two-thirds of the soil volume above the depth of $40 \mathrm{~cm}$ was not participating in transport. At the end of the 2-week solute application period, each plot received sprinkler irrigation which distributed the water at a much smaller scale of uniformity across the plot surface.

In an attempt to model the influences of the time delay of sampling and the dripper application, the following assumptions were made. First, it was assumed that the experiments were at steady state, with the flux at each site defined by the average daily rate of net applied water $\left(d_{N A W}\right)$ over the final five days of irrigation prior to a sampling event. Irrigations were performed daily during a 4-hour period starting at 0600 ; thus the sampling time delay, $t_{d}$, was calculated as the time starting from 24 hours following the commencement of the final irrigation until the midpoint of the sampling period. For example, if sampling began 48 hours following the last irrigation, and the sampling period was 12 hours long, then $t_{d}$ would be 1.25 days. The second assumption was that with the flux application of solute, two-thirds of the soil solution in the top $40 \mathrm{~cm}$ of the profile was bypassed as a result of the dripper system. These two assumptions are represented by (5), which provides a modified estimate of $N A W_{c m}$ :

$$
N A W_{c m} \equiv N A W-\frac{N A W_{0}}{2}+t_{d} d_{N A W}+W \int_{0}^{40} \theta_{v}(s) d s
$$

where $t_{d}$ is in days, $d_{N A W}$ is in centimeters per day, and $W$ is $\frac{2}{3}$ for plumes created with flux application and 0 for the resident experiment. This modified estimate of $N A W_{c m}$ was used to create Figure $14 b$, which provides a much better estimate of the location of the plume center of mass. However, the steady-state assumption does not fully explain the deep movement of $12 \mathrm{RLb}\left(N A W_{c m}=103.4 \mathrm{~cm}\right)$. No significant difference was seen when the prediction was based on local gravimetric water content measurements. The steady-state assumption implied in (5) obviously does not explain all of the underprediction on this site. Disregarding sampling $12 R L b$, it appears that the field average mean pore water velocity and the local mean solute velocity were the same.

\section{SUMMARY AND CONCLUSIONS}

The experimental procedures described herein provide a novel approach for examining field scale, three-dimensional solute transport processes. The reasonable mass recovery estimates obtained, as well as the correlation between chloride and nitrate measurements, provide assurance of the quality of the data. The detailed study of the physical properties within the field suggested that the site can be characterized as relatively homogeneous across the field within a given layer or depth, with a high degree of vertical variability between these layers. A slight slope in the layers in a southerly direction was also noted. These observations were supported by examining the experimental mean plume transport within the field. The accurate prediction of the chloride plume center of mass in the flux experiment as a function of NAW from the field-averaged properties is an important result which encourages the hope that solute transport may be predicted from independently measured soil properties or parameters.

The mean movement of the water-soluble boron fraction was also similar across the field despite boron's being obviously retarded relative to chloride transport. Furthermore, the rate of decrease in the water-soluble $B$ mass recovery with increasing time was similar for the 1.5 -m plots in the first study phase. This suggests that B sorption occurred uniformly within the field. The bias in a southerly direction in the location of the center of mass (which agrees with the observed southerly layering) provides further evidence that observed or measurable properties can be useful in estimating transport phenomena. However, a more critical objective, from both a theoretical and applied perspective, is in relating the observed dispersion process (both transverse and longitudinal) to measurable properties. The dispersive nature of the vertical plume transport in these experiments is discussed in a companion paper [Ellsworth and Jury, this issue].

Acknowledgments. The authors would like to thank the Electric Power Research Institute, the Southern California Edison Company, and the University of California, Riverside, Toxic Substances Research and Training Program for financial assistance on this project. Appreciation is also expressed to D. A. Barry for many helpful comments and suggestions pertinent to this research.

\section{REFERENCES}

Barry, D. A., J. Coves, and G. Sposito, On the Dagan model of solute transport in groundwater: Application to the Borden site, Water Resour. Res., 24(10), 1805-1817, 1988.

Bresler, E., and G. Dagan, Convective and pore scale dispersive solute transport in unsaturated heterogeneous fields, Water Resour. Res., 17(6), 1683-1693, 1981.

Butters, G. L., Field scale transport of bromide in unsaturated soil, $\mathrm{Ph} . \mathrm{D}$. dissertation, 243 pp., Univ. of Calif., Riverside, 1987.

Butters, G. L, and W. A. Jury, Field scale transport of bromide in an unsaturated soil, 2, Dispersion modeling, Water Resour. Res., 25, 1583-1589, 1989.

Butters, G. L., W. A. Jury, and F. F. Ernst, Field scale transport of bromide in an unsaturated soil, 1, Experimental methodology and results, Water Resour. Res., 25, 1575-1581, 1989.

Crain, I. K., and B. K. Bhattacharyya, Treatment of nonequispaced two-dimensional data with a digital computer, Geoexploration, 5, 173-194, 1967.

Dagan, G., Solute transport in heterogeneous porous formations, $J$. Fluid Mech., 145, 151-177, 1984.

Dagan, G., Theory of solute transport by groundwater, Annu. Rev. Fluid Mech., 19, 183-215, 1987.

Day, P. R., Particle fractionation and particle size analysis, in Methods of Soil Analysis, Monogr. 9, edited by C. A. Black, pp. 545-567, American Society of Agronomy, Madison, Wis., 1965.

DeGroot, M. H., Probability and Statistics, 2nd ed., AddisonWesley, Reading, Mass., 1986.

Dorrenbos, J., and W. O. Pruitt, Guidelines for predicting crop water requirements, Irrig. and Drain. Pap. 24, Food and Agric. Organ., Rome, 1975.

Elabd, H., I. Porro, and P. J. Wierenga, Estimation of field transport parameters using the convection dispersion equation, Validation of Flow and Transport Models for the Unsaturated Zone: Conference Proceedings, Res. Rep. 88-ss-04, 545 pp., Dep. of Agron. and Hort., N. M. State Univ., Las Cruces, 1988.

Ellsworth, T. R., Field-scale spatial and temporal characterization 
of solute plume transport through unsaturated porous media, Ph.D. dissertation, Univ. of Calif., Riverside, 1989.

Ellsworth, T. R., and W. A. Jury, Three-dimensional solute plume transport through an unsaturated field soil, topical report, Elec. Power Res. Inst., Palo Alto, Calif., in press, 1991.

Ellsworth, T. R., and W. A. Jury, A three-dimensional study of solute transport through unsaturated, layered, porous media, 2 , Characterization of vertical dispersion, Water Resour. Res., this issue.

Freyberg, D. L., A natural gradient experiment in a sand aquifer, 2 , Spatial moments and the advection and dispersion of nonreactive tracers, Water Resour. Res., 22(13), 2031-2046, 1986.

Geisser, S., The predictive sample reuse method with applications, J. Am. Stat. Assoc., 70, 320-328, 1975.

Goldberg, S., and R. A. Glaubig, Boron adsorption on California soils, Soil. Sci. Soc. Am. J., 50, 1173-1176, 1986.

Jasmund, K., and B. Linder, Experiments on the fixation of boron by clay minerals, Proc. Int. Clay Conf., 1972, 399-412, 1973.

Jaynes, D. B., R. C. Rice, and R. S. Bowman, Independent calibration of a mechanistic-stochastic model for field-scale solute transport under flood irrigation, Soil. Sci. Soc. Am. J., 52(6), 15411546, 1988.

Killey, R. W. D., and G. L. Moltyaner, Twin Lake tracer tests: Setting, methodology, and hydraulic conductivity distribution, Water Resour. Res., 24(10), 1585-1612, 1988.

Kung, K.-J. S., Preferential flow in a sandy vadose zone, 1, Field observation, Geoderma, 46, 51-58, 1990.

Mackay, D. M., D. L. Freyberg, P. V. Roberts, and J. A. Cherry, A natural gradient experiment on solute transport in a sand aquifer, 1, Approach and overview of plume movement, Water Resour. Res., 22(13), 2017-2029, 1986.

McArthur, R. D., An evaluation of sample designs for estimating a locally concentrated pollutant, Commun. Stat. Simulations, 16, 735-759, 1987.

McCord, J. T., D. B. Stephens, and J. L. Wilson, Field-scale unsaturated flow and transport in a sloping uniform porous medium: Field experiments and modeling considerations, Flow and Trans- port Models for the Unsaturated Zone: Conference Proceedings. Res. Rep. 88-ss-04, 545 pp., Dep. of Agron. and Hort., N. M. State Univ., Las Cruces, 1988.

Russo, D., W. A. Jury, and G. L. Butters, Numerical analysis of solute transport during transient irrigation. 1, The effect of hysteresis and profile heterogeneity, Water Resour. Res., 25(10). 2109-2118, 1989a.

Russo, D., W. A. Jury, and G. L. Butters, Numerical analysis of solute transport during transient irrigation, 2 , The effect of immobile water, Water Resour. Res., 25(10), 2119-2127, 1989 b.

Sposito, G., The Surface Chemistry of Soils, Oxford University Press, New York. 1984.

Sposito, G., and D. A. Barry, On the Dagan model of solute transport in groundwater: Foundational aspects, Water Resour. Res., 23(10), 1867-1875, 1987.

Stephens, D. B., A. M. Parsons, E. D. Mattson, K. Black, K. Flanigan, R. S. Bowman, and W. B. Cox, A field experiment of three-dimensional flow and transport in a stratified soil, Validation of Flow and Transport Models for the Unsaturated Zone: Conference Proceedings, Res. Rep. 88-ss-04, 545 pp., Dep. of Agron. and Hort., N. M. State Univ., Las Cruces, 1988.

Woodruff, G. A., Soil Survey of San Bernardino County, Southwestern Part, California, pp. 1-63, U.S. Government Printing Office, Washington, D. C., 1980.

T. R. Ellsworth, Department of Agronomy, University of Illinois at Champaign-Urbana, 1102 South Goodwin Avenue, Urbana, IL 61801 .

F. F. Emst and W. A. Jury, Department of Soil and Environmental Science, University of California, Riverside, CA 92521.

P. J. Shouse, U.S. Salinity Laboratory, 4500 Glenwood Drive, Riverside, CA 92501.

(Received March 21, 1990; revised November 5, 1990; accepted January 15, 1991.) 